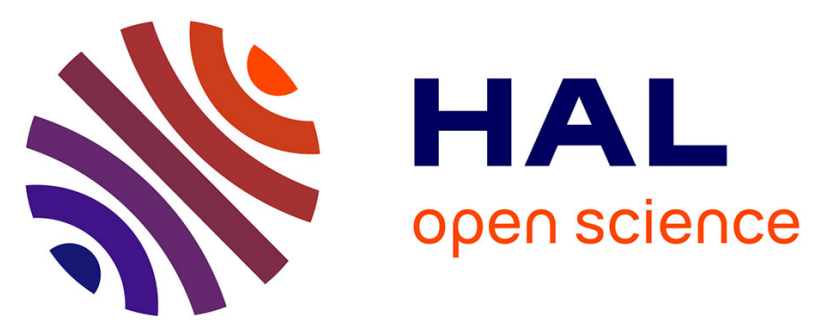

\title{
Assessment of trace metals during episodic events using DGT passive sampler: A proposal for water management enhancement
}

J.D. Villanueva, Philippe Le Coustumer, Frédéric Huneau, Mikael

Motelica-Heino, T. Perez, R. Materum, Ma. Victoria Espaldon, S. Stoll

\section{To cite this version:}

J.D. Villanueva, Philippe Le Coustumer, Frédéric Huneau, Mikael Motelica-Heino, T. Perez, et al.. Assessment of trace metals during episodic events using DGT passive sampler: A proposal for water management enhancement. Water Resources Management, 2013, 27 (12), pp.4163-4181. 10.1007/s11269013-0401-5 . insu-00853458

\section{HAL Id: insu-00853458 \\ https://hal-insu.archives-ouvertes.fr/insu-00853458}

Submitted on 22 Aug 2013

HAL is a multi-disciplinary open access archive for the deposit and dissemination of scientific research documents, whether they are published or not. The documents may come from teaching and research institutions in France or abroad, or from public or private research centers.
L'archive ouverte pluridisciplinaire HAL, est destinée au dépôt et à la diffusion de documents scientifiques de niveau recherche, publiés ou non, émanant des établissements d'enseignement et de recherche français ou étrangers, des laboratoires publics ou privés. 
Assessment of trace metals during episodic events using DGT passive sampler: A proposal for water management enhancement

\section{J. D. Villanueva ${ }^{1,2}$, P. Le Coustumer ${ }^{1}$, F. Huneau ${ }^{3,4}$, M. Motelica-Heino ${ }^{5}$, T.R. Perez ${ }^{6}$, R.

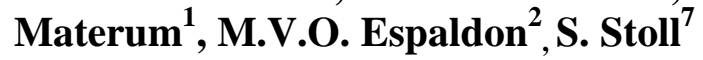

${ }^{1}$ Université de Bordeaux, EA 4592 Géoressources \& Environnement, ENSEGID, 1 allée F. Daguin, F33607 Pessac, France

${ }^{2}$ University of the Philippines Los Baños, School of Environmental Science and Management,

College, Laguna 4031, Philippines

${ }^{3}$ Université de Corse Pascal Paoli, Faculté des Sciences et Techniques, Laboratoire d'Hydrogéologie, Campus Grimaldi, BP 52, F-20250 Corte, France

${ }^{4}$ CNRS, UMR 6134, SPE, F-20250 Corte, France

${ }^{5}$ Université d'Orléans, UMR CNRS 6113, ISTO, Campus Géosciences, 1A rue de la Férollerie, F41071 Orléans, France

${ }^{6}$ Ateneo de Manila University, Department of Environmental Science, Loyola Height, Quezon City 1108, Philippines

${ }^{7}$ Institute Forel, University of Geneva, Environmental Physical Chemistry, 10 rte de Suisse, 1290 Versoix, Switzerland

Contact author:

E-mail: plc@lnet.fr 


\begin{abstract}
The potential of the Diffusive Gradient Thin-Films (DGT) as a supplemental method for water quality monitoring was employed has been tested through 3 sampling campaigns to measure the trace metals $(\mathrm{Cd}, \mathrm{Co}, \mathrm{Cr}, \mathrm{Cu}, \mathrm{Pb}, \mathrm{Ni}$ and $\mathrm{Zn})$ present in the surface water of a highly urbanized river. Specifically, the study done in the Pasig River (Philippines) seeks to: assess the applicability of DGT passive sampler in an urban context exhibiting highly contrasted hydrological conditions (greatly influenced by episodic events) and sediment disturbance (dredging) and provide proposal for a better water management. The results indicate that: (1) DGT is highly recommended as part of a routine analysis for water quality monitoring; (2) DGT are able to capture the fluxes even in very contrasted flow regimes; (3) DGT are suitable to trace the labile fluxes of metals from the lake to the estuary; and (4) at the confluence of the Marikina River water management should be intensified. Moreover, recommendations were made for developing pertinent water monitoring protocol and management scheme.
\end{abstract}

Keywords Trace metals, DGT, in-situ passive sampling, surface water, Pasig River, Philippines 


\section{Introduction}

Pollution of surface water is a worldwide issue of environmental concern (Ouyang 2005). Among the water bodies, estuary is challenging. The manner of using (Hartnett et al. 2011), the interfaces among the saline gradient and the continuous tidal actions make the system diverse and complex (Winn et al. 2003). Trace metals are among the few persistent contaminants introduced into this type of water resource (Severini et al. 2009). Their distribution (Zwolsman et al. 1997) and bioavailability in the estuaries are now of major environmental concern in terms of water management (Masson et al. 2011).

The development of monitoring approaches requires essential elements of the water system under study such as: (1) being adapted; (2) giving representative information; and (3) entailing consistent and specific approach or methodology (Strobl and Robillard 2008). Sampling approaches, normally, involves conventional spot and grab sampling for water quality monitoring. However, this can disturb the natural chemical reaction in the samples aside from the fact that these trace metals are very sensitive so that accuracy of data can be a problem. Accordingly, in-situ measurements are being advised. It can give more reliable information on the distribution of the chemical species in natural water (Zhang and Davison 1995; Lu et al. 2002; Allan et al. 2008; Vrana et al. 2005). Another difficulty is the lack of reliable and low-cost water quality sensors for continuous monitoring (Aisopou et al. 2012). Normally, the budget constraint should also be considered but the analytical procedure must not be at stake because of this reason.

The emerging in-situ passive sampling appears to give good responses to the above mentioned problems. Additionally, advantages include (Graveline et al. 2010): (1) allowing accumulated weighted average or high-time resolution of concentration (making it possible to assess the total load carried by a stream over a given period of time); and (2) capable of measuring the presence of the contaminants that the conventional sampling could not be able 
to detect (passive samplers can detect even trace to ultra trace level). From the actual experience, this: (3) in terms of prioritization, can be able to locate the most challenging (deteriorating water quality) area at a shorter period of time; and (4) does not need huge quantity of water to transport and store in the laboratory before analysis. Inferences can be made since it has an operationally defined measure of DGT-labile trace metals that contains the "bioavailable" fraction (INAP 2002). Success on the use of the DGT in tracing and monitoring labile trace metal species had been documented (Alexa et al.2009; Docekalova and Divis 2005; Pérez and Anderson 2009; Vystavna et al. 2012a; Sherwood et al. 2009; Munksgaard and Lottermoser 2010).

In this paper, the trace metals such as Cadmium (Cd), Cobalt (Co), Chromium (Cr), Copper $(\mathrm{Cu})$, Nickel $(\mathrm{Ni})$, Lead $(\mathrm{Pb})$ and Zinc $(\mathrm{Zn})$ : (a) in total, using the conventional method, normally, employed by the local water authorities and (b) DGT-labile metal fractions, using the DGT technique were evaluated to help in determining the water quality state of an estuary in the Philippines. The use of the DGT is a pilot study in this country, which can provide a more holistic situation for water resource managers on the trace metal distribution and bioavailability. The aim of this paper is not to compare the total to DGTlabile trace metals but to give an overview of their behavior in response to the captured episodic events and to provide a supplemental water quality measurement strategy for a better water resource assessment.

\section{Materials and Methods}

\subsection{Study site}

The surface area of the Pasig River is $1,710 \mathrm{~km}^{2}$. This stretches to about $27 \mathrm{~km}$ with a water volume of 6.5 million $\mathrm{m}^{3}$. The width is from $62 \mathrm{~m}$ to $120 \mathrm{~m}$ with an average of about $90 \mathrm{~m}$. The shallow part is around $1 \mathrm{~m}$, while, the deepest is $5 \mathrm{~m}$. The shoreline length is almost 5 
$\mathrm{km}$. Average low flow is $12 \mathrm{~m}^{3} / \mathrm{s}$, with a maximum flow of $275 \mathrm{~m}^{3} / \mathrm{s}$ (PRRC 2009) during dry and wet seasons respectively. Four major and important tributaries drain to this river. These are the San Juan River, Marikina River, Napindan River and Pateros-Taguig River. The minor tributaries, around 43, have the surface area ranging from $2 \mathrm{~km}^{2}$ to $400 \mathrm{~km}^{2}$.

As the main river in the National Capital Region (NCR), commonly called Manila (c.a. 11,500,000), joining the Manila Bay (downstream), to the west, and the Laguna Lake (upstream), to the east (Figure 1). It is influenced by fluxes from industries, residential houses, informal settlers, and other commercial areas. The river also receives wastewaters from surrounding cities where about 50 percent of the pollution load comes from the industry with an equal percentage coming from domestic liquid wastes (Cruz 1997). Industries include: mill factories, ceramic and tile industries, steel industry, oil depots, chemical industry, sugar refinery, power plant, food and beverage and gas stations. Despite the alarming water quality, the river is still in function such as for swimming, fishing, navigation (boats, ferries, ships, etc.), growing of lilies and the riparian area serve as recreational area such as parks.

The Pasig River was selected for this pilot activity since: (1) it is one of the major and important river basins in the Philippines; (2) the highly urban situation and lack of water treatment plants (although, industries are mandated to have such facilities) pose water quality problems such as contamination; (3) the condition such as low and high flow permits the hydrological representativeness; and (4) the chosen sampling sites are under the water surveillance of the local authorities mainly headed by the Pasig River Rehabilitation Commission (PRRC).

\subsection{Sampling}

Four sampling points were considered (Figure 1) taking into account the river sections (upstream, midstream and downstream), the salinity gradient and impacts of anthropogenic 
activities. The approximate distance of each sampling point from each other is 7 kilometers. Point 1 was at the mouth of the river, towards the Manila bay, Points 2 (near San Juan River) and Point 3 (close to the Marikina River) were located in the midstream of the river and Point 4 is near the outlet of Laguna Lake at the eastern part of the Pasig River.

Seasonal variations (dry and wet) were taken into account so sampling was done three times as seen in Table 1. Pasig River is classified under the Climate Type I under the Philippine Corona System which has a two (2) distinct seasons: wet (May to October) and dry (November to April). The seasonal variation influences the hydrological condition of the river (Tsakiris 1988) so the sampling campaigns were done in the months of April-May 2010, January 2011 and May-June 2011. These are representatives of the intermediate (between the dry and wet) period (Sampling Period 1); dry season (Sampling Period 2) and start of the wet season (Sampling Period 3). To fully capture the hydrological condition (especially the intermediate period) and estuarine ecotone of this river, more than 2 weeks ( $\mathrm{n}=18$ days) was selected. In addition the length of the deployment period chosen corresponds to the recommended average immersion in water (about minimum of a week to a month).

However, unexpected events which can potentially have some bearings on hydrological conditions were encountered: Sampling Period 1 experienced dry season; Sampling Periods 2 and Period 3 covered wet period (Table 1). Compared to the normal precipitation rate, for the year 2010, April is a little bit higher $(0.43 \%)$ than the normal while May is only 3.43\% of the normal; for the year 2011, January, May and June were higher (4.92 times, $0.19 \%$ and twice, respectively) than the normal precipitation rate.

The country during these periods experienced climatic variation called the El Niño Southern Oscillation (ENSO) phenomenon. This phenomenon is characterized by "warm events or drought" due to the movement of the warm sea water from the western Pacific followed by the "wet events" coming from the easterly trade-wind-induced flows of colder 
water from the eastern Pacific (Harger 1995). The seasonal surface circulation in the Philippine archipelago affects the surface water movement with strong variation on currents and tides (Han et al. 2009). In addition to this situation, during the $1^{\text {st }}$ sampling period, simultaneous to the sampling activity, a dredging activity was on-going. Improving the canal system specially in diverting the water during floods to the Napindan Hydraulic area was one of the objectives.

Accessibility and security of the DGT probes were also considered as the probes have to be immersed in the river for a long period. Environmental parameters such as $\mathrm{pH}$, salinity and conductivity, water temperature and dissolved oxygen (DO) were determined in-situ using an automatic sampler, YSI 6600 V2 data sonde. The total organic compound (TOC) of the Pasig River ranges from 3.4 to $4.5 \mathrm{mg} / \mathrm{L}$ during May 2010 and 3.5 to $7.4 \mathrm{mg} / \mathrm{L}$ for January 2011 (Materum 2010). In parallel, conventional water sampling following the normal procedure of the local water authorities using bottles was performed. The unfiltered water samples were collected using acid-rinsed $\left(1: 10 \mathrm{HNO}_{3}\right) 150 \mathrm{~mL}$ Nalgene bottle ( $\mathrm{n}=2$ per site) during each sampling period. These then were stored in a refrigerator.

The DGT probes $(n=2)$ were left fully-immersed for a period of 18 days in each sampling station placed in a specially manufactured container made in bamboo (Figure 2). Field blank $(\mathrm{n}=1)$ per sampling campaign was provided. Cooling compartments and precleaned re-sealable plastic storage bags properly marked were prepared before the retrieval. Upon retrieval, each DGT was rinsed with deionized water (Milli-Q at 18 mega ohms $\mathrm{cm}$ ) and immediately placed in the pre-cleaned resealable plastic bags then put in the cooling compartment. Subsequently, DGTs were kept in the refrigerator until the extraction was performed. 


\subsection{Materials and Quality Control}

The nitric acid used is Fisher Scientific Analar grade. DGTs were purchased at the DGT Research Ltd, Lancaster, UK. DGT field blanks ( $\mathrm{n}=3$ ) were extracted and analyzed using the same procedure done for the DGTs deployed in the river. In each of the water quality parameters considered, laboratory procedural blanks were done and detection limit were determined by getting the standard deviation of the blank solution multiplied by three (Zheng et al. 2012; Pattke et al. 2012). The blank values were then subtracted to the values obtained from the field-deployed DGTs. Precision of the replicates of all the total trace metals collected conventionally is $10 \%$. While, the Relative Standard Deviation (RSD) obtained from DGT is shown in Table 2. RSD from the DGT samplers seemed to be higher than the values obtained from the total trace metals.

\subsection{Determination of trace metals}

\subsubsection{Total trace metals (on conventional approach: water samples from bottles)}

At the laboratory, since samples are from an estuary, dilution using deionized water (Milli-Q) was applied and prepared in a Teflon centrifuge tube. The protocols for clean room; laboratory sample handling including pretreatment for total trace metal; and the use of inductively coupled plasma-mass spectrometry (ICP-MS) and instrument analysis followed the analysis of surface water for trace metal elements by ICP-MS guidelines (Shafer and Overdier 1995). Measurement of selected trace metals was performed using ICP-MS equipment Agilent Technologies HP 4500 Series 100. $10 \mathrm{~mL}$ each of previously acidified samples (using $65 \% \mathrm{HNO}_{3}($ Merck Suprapur®)) were filtered with $0.45 \mu \mathrm{m}$ syringe filter cartridges (Millipore Millex®-LCR hydrophilic PTFE, $25 \mathrm{~mm}$ ). Calibration curves of the trace metals of interest were made beforehand using Merck CertiPUR® ICP multielement standard solution VI for ICP-MS. TMDA-70 (lot 1007), a water sample from Lake Ontario 
fortified with trace metals purchased from Environment Canada, served as the certified reference material for verifying the quality of the analytical results.

\subsubsection{DGT-labile trace metals (in-situ passive sampling)}

In the laboratory, resin layers were carefully removed using Teflon tweezers. Each resin was placed in a Teflon centrifuge tube with $1 \mathrm{~mL}$ of $1 \mathrm{M}$ of $\mathrm{HNO}_{3}$ (Aung et al. 2008). To allow elution, the solutions were kept for $24 \mathrm{~h}$. Dilution of the eluent using deionized (Milli-Q) was applied, subsequently. The solutions were then analyzed using ICP-MS. Details on the process are extensively discussed in many journal articles already (Zhang and Davison 1999 and Li et al. 2005). The environmental concentration of trace elements was calculated using the following formula (DGT Research 2002):

$$
C_{D G T}=\frac{M \Delta \mathrm{g}}{\mathrm{D} \mathrm{At}} \quad(1)
$$

Where, $C_{D G T}$ is the measured DGT labile trace metal concentration; $A$ is the exposed area of the DGT probe; $\Delta g$ is the thickness (PAA hydrogel); $D$ is the diffusion coefficient which is water temperature dependent (obtained from the study of DGT Research 2002); $t$ is the total time of deployment; and $M$ is the mass of the labile metal captured at the binding phase. The latter is calculated as follows:

$$
M=\frac{\mathrm{C}_{\mathrm{el}}\left(\mathrm{V}_{\mathrm{gel}}+\mathrm{V}_{\mathrm{HNO3}}\right)}{f_{e}}
$$

Where, $C_{e l}$ is the concentration of the metals in the elution solution; $V_{g e l}$ is volume of the resin gel; $V_{H N O 3}$ is the volume of $\mathrm{HNO}_{3}$ added to the resin and $f_{e}$ is the elution factor. 


\section{Results and Discussions}

\subsection{Variation of routine environmental parameters}

Environmental factors such as physical, chemical and biological constituents of the water quality affect the physical and chemical condition of a water body (Wei et al. 2009; Vystavna et al. 2012b). As shown in Table 3, the results on the routine environmental parameters indicate spatial and temporal variation of dissolve oxygen (DO), salinity and conductivity. The environmental factors were evidently influenced by the episodic events during the sampling periods mostly expressed in DO. The DO exhibited different oxic conditions through periods.

The Department of Environment and Natural Resources (DENR), in Philippines is the main authority which manages and implements the water regulations. One of the regulations is the Department Administrative Order 34 (DAO) which is for the Water Usage and Classification or Water Quality Criteria. It requires a minimum of $5 \mathrm{mg} / \mathrm{L}$ for DO. Periods 1 and 3 failed to comply in this regard. However, compared to the set limit of the Canadian Council of Ministers of the Environment (CCME 1996) for marine and estuaries, this is lower, DO should be above $8 \mathrm{mg} / \mathrm{L}$. In this case, only the upstream met the limit.

\subsection{Distribution of trace metals}

\subsubsection{Total trace metals}

The range of concentration of total trace metals is presented in Table 4. Period 1 gave the highest total trace metal concentration among all the periods with values of an order of magnitude to two more than the 2 other periods. This is the case for $\mathrm{Cr}, \mathrm{Cu}$ and $\mathrm{Cd}$. Others $(\mathrm{Pb}, \mathrm{Ni}$ and $\mathrm{Zn})$ have close range of concentrations for the 3 periods with some having problem of under the limit of detection. The only metal which increased its concentration during the last period is Co. 
DAO 34 has recommended water quality limit for $\mathrm{Cr}, \mathrm{Cd}$ and $\mathrm{Pb}$ but $\mathrm{Cu}$ is in dissolved form. If this will be followed, then $\mathrm{Cr}$ in Period 1 sampling points 1 and 3 and $\mathrm{Cd}$ concentrations in all sampling points during Period 1 were above the limit (Figure 3). But $\mathrm{Pb}$

is within the limit. Figure 5 shows the total trace metal concentration percent contribution along periods. Notably, with reference to the lake, all trace elements increased as they reach Point 3.

The results obtained revealed that some trace metals were not measured as depicted by the values of under the limit of detection (Table 4) such as in Period 1, with the noticeable exception of $\mathrm{Ni}$ at point 3. It was then observed during the Period 2: $\mathrm{Co}, \mathrm{Ni}$ and $\mathrm{Cd}$ at point 4; and Period 3: $\mathrm{Cu}$ and $\mathrm{Cd}$. Evidently, some reasons can be pointed out: (i) some trace metals are in very low concentration, (ii) sampling volumes were not sufficient, and (iii) problems occurred during the analysis. This is even if the sampling and analytical procedures had been in the best possible conditions and norms following also the recommendations of the scientific community and local authorities. Thus, it shows the limitations of the sampling procedure made in the case the trace metals ( $\mathrm{Co}, \mathrm{Ni}$ and $\mathrm{Cu}$, for example, during Periods 2 and 3).

\subsubsection{DGT-labile trace metals}

The concentrations varied through periods. At Period 1, the concentrations decreased except for $\mathrm{Ni}$ and $\mathrm{Zn}$. Increase then followed at Period 2 except for $\mathrm{Co}$ and $\mathrm{Pb}$. At the last period, only $\mathrm{Cr}$, Ni and $\mathrm{Cd}$ continuously increased. Similar to the total trace metals, most of the concentrations increased at the confluence of Marikina River (sampling point 3), with reference to the lake. Figure 4 illustrates the calculated DGT concentration $\left(\mathrm{C}_{\mathrm{DGT}}\right)$ in each period and each site. Periods 1 and 2 exhibited higher value than Period 3, except for $\mathrm{Zn}$ which was quite constant during all the sampling periods. Period 2 gave the highest values compared to the others with the concentration of an order of magnitude to two, particularly 
for Cr. For all the periods, it seemed that the DGT-labile trace metals did not exceed the recommended water quality criteria on dissolved fraction (Figure 4) basing on the U.S. Environmental Protection Agency (USEPA 2012) and DAO 34 for $\mathrm{Cu}$. Co, on the other hand, is not included in the criteria due to a lack of toxicological data (Diamond et al. 1992).

Contrary to the results obtained in measuring the total trace metals there is no missing data. The DGT probes were able to record the DGT-labile trace metals in terms of detection; managing the problems of trace level quantities and sampling and analytical procedures. All the probes deployed served their function and was able to deliver the necessary information (in terms of concentrations and fluxes). The values obtained are in the range of the ng/L. For most of trace metals, the DGT-labile forms are lower than the observed total fractions, which is a normal/logical trend. However, there are some exceptions (Table 4) observed during the $2^{\text {nd }}$ period, where DGT-labile concentrations of $\mathrm{Cd}$ and $\mathrm{Cr}$ exceeded the total fractions. This is not common but can be attributed to: (1) different sampling procedures obtained; (2) manner of sampling in terms of time (as DGT uses the concept of weighted average time while the conventional procedure is instantaneous); (3) trace metal behavior, itself, depending on how it responds to the natural system or episodic event (e.g. surface-run-off, atmospheric contribution, etc.) which can induce higher level of labile trace metals.

\subsubsection{Trend of trace metals}

Concentrations of the trace elements during Period 1 can be attributed to the dredging activity in the Pasig River as the silts and sediments are resuspended to the water column. Sediment disturbance can cause mobilization of contaminants (Eggleton and Thomas 2004) and affects the affinity of the trace elements. Dispersion of the trace metal in the water column is predominantly of the particulate phase and increase in dissolved concentration is mostly related to the environmental condition (Van den Berg et al. 2001). 
During Period 2, precipitation rate increased the water flow and turbidity explaining the trace metal trend. Most of the measured DGT-labile trace metals are of highest concentration. Also high rainfall rate caused substantial elevated urban surface run-off which came from different sources (agricultural, industrial, residential, etc.) accompanied by the trace elements captured from the atmosphere. This condition then allowed a rapid horizontal mobility of the trace elements going to the bay. The concentration of the trace metals could even be higher if not for the flushing and dilution effect.

Both Periods (2 and 3) experienced rainfall events. In which, sediment resuspension can also be expected. The strong tidal currents releases significant amount of trace metals in the water column (Wu et al. 2005). Table 1 shows that the amount of rainfall accumulated for Periods 2 and 3 (within the sampling dates) are almost the same. However, the trace metal concentrations in Period 3 are dissimilar to Period 2. The difference in concentrations in these 2 periods seems notable. The rainfall pattern can give an explanation. Both periods (2 and 3) experienced run-off and atmospheric contributions but the dilution effect was higher in the last period. In actual fact, 18 days before the sampling campaign was conducted for Period 2, $13 \mathrm{~mm}$ amount of rainfall was accumulated. Whereas, the same number of days prior to the sampling campaign for Period 3, the generated rainfall was $123.6 \mathrm{~mm}$. Thus, added to the creation of a washing effect prior to the sampling Period 3.

It is observed that the river seemed to display progress through periods. Even so, the lack of water treatment plants for domestic sources and uncontrollable dumping can still bring the river to its old problematic state. Also although, DAO 35 which is the Revised Effluent Regulations of 1990 required industries to have treatment plants, the non-compliance is a problem. The continuous release of chemical substances will adversely affect the surface water (Hartman et al. 2006). 


\section{Water management implication and recommendation}

Urbanization and rapid developments affected the water quality of the Pasig River dramatically. The consistent increase of most of the trace elements through periods from the lake to sampling point 3 is interesting. This can imply that in between sampling points 3 and 4 or within sampling point 3 , itself, there are regular contributors. Although, it is obvious that each sampling points contribute as well, the area can be identified as a priority by the water management authorities. In addition, among the trace metals, the contribution of $\mathrm{Zn}$ and its trend seemed different both in total and labile-DGT measurements. $\mathrm{Zn}$ is a typical urban related pollution (Thévenot et al. 2007; Mazzei et al. 2008).

The research conduct affirms that monitoring helps in understanding various hydrological processes and is a useful tool for the water managers (Khalil et al. 2010). The results obtained can provide sound and useful information that is needed in the assessment, restoration, and protection of the aquatic ecosystem (Ouyang 2005). Furthermore, it aids in ensuring the water quality compliance to the water regulations or guidelines (Aisopou et al. 2012). Since the monitoring system is usually limited, a more practical, reliable and economical sampling approach is necessary. Consequently, it should commence with these essentials:

1. Defined objectives (until how far can it reach);

2. Kind of results expected;

3. Specific target elements and analytical partitions that are of main interest; and

4. The appropriate methodologies and protocol.

To better interpret the data acquired, the determination of the effect on the trace elements on the aquatic ecosystem is important to understand (Gay and Maher 2003; Morilli and Usero 2008). For instance, the trace metals in flowing water can be into (Wetzel 2001 c.f. Gibbs 
1973): (1) ionic forms; (2) complexed with organic materials; (3) adsorbed to and precipitated onto solids; and (4) incorporated in crystalline structures. Hence, total trace metals can be measured if the particulate fractions are one of the concerns. This is useful to describe the currents state of the river. However, the total concentrations may not reflect the real bioavailability (portion that can enter into the systemic circulation) if health risks are of major concern (Moreda-Piñeiro et al. 2012). Even the dissolved fractions cannot serve as good predictors in bioavailability. Rather, the free metal ion complexes should be the one to consider (Janssen et al. 2003; Meyer 2002; Alfaro-De la Torre et al. 2000). This is because the bioavailability depends on chemical form and the free metal ion activity exhibits its relationship with the biological effects (Campbell 1995).

For these reasons and from the advantages given in the studies (Zhang and Davisson 1995; Sondergaard et al. 2008; Yapici et al. 2008) involving this technique, DGT was employed. The emphasis is on its capability to do quantitative measurements of labile species (ionic forms and easily dissociable complexes can be taken up) that more likely represent the bioavailable fractions of the trace metals (Schintu et al. 2008). Although, this paper is not a promotion of DGT, instead it is taking advantage on the use of the emerging technology in order to achieve an enhanced water management system. In this research, there is a strong indication that using DGT sampler as an additional, if not alternative, sampling technique is highly recommended. This is in the bearing of its usefulness and being effective, mostly as if it concerns bioavailability and drinking water issues, for routine water quality monitoring.

From the sampling experiences and output, a sampling strategy (Figure 6) is proposed. The conventional approach can be applied both for the total and dissolved trace metals while the passive sampling approach in this case refers to the use of DGT. The graphs could represent each of the scenarios encountered during the sampling campaigns. So, three (3) scenarios were depicted: (1) Scenario 1 describes the dry event but with the sediment 
disturbance (introduced episodic event) caused by dredging; (2) Scenario 2 is from wet season to rainfall events; and (3) Scenario 3 is a wet event to continues rainfall. Of course, the concentration can vary but the figures can give ideas on how the concentrations can be somehow expected. The curves in dotted and broken lines represent the predicted uncertainty in each of the scenario. Assuming that the hydrological condition is greatly affected by the climatological condition such as precipitation (Nalbantis and Tsakiris 2009; Akrami et al. 2013), RSD (relative standard deviation) was computed using this data (Table 1) obtained in each period (Period 1: \pm 3.45 ; Period 2: \pm 2.34 ; Period 3: \pm 1.59 ). However, another source of uncertainty is the contribution of dredging. Therefore, we can assume that RSD could be higher.

There could be different stages that can be drawn. In scenario 1 there are: Stage 1dredging starts; Stage 2 - dredging continues and the trace metals increase; and Stage 3 - there could be a point wherein the concentrations could stabilize (could be quick or long time) before it further increase or decrease. For scenario 2: Stage 1-start of the rainfall; Stage 2rainfall continues accompanied with run-offs; Stage 3- peak of the concentration; Stage 4dilution starts; and Stage 5 - washing effect. Scenario 3 is the last part of scenario 2, wherein, Stage 1 is the same with Stage 4 and Stage 2- washing effect continues.

Figure 6 would like to imply that series of grab collection in each of the scenario are needed (and should be frequented) in order to satisfy the quality of data needed using the conventional approach. Scenarios 1 and 3 need at least 4 times of water sample collections. Scenario 2 requires more water sample collection than the 2 other scenarios.

The idea of DGT follows the time-weighted average (at the specific time of immersion). The sampling design for Periods 1 and 3 can have at least 2 ways. It can be either Approach 1 that allows temporal variation or Approach 2 that covers the whole duration of the event at a given time. The approaches are described below: 
Approach 1. $\quad D G T 1+D G T 2=C_{D G T}$

Approach 2. $D G T 3=C_{D G T}$

Approach 3. $D G T 1+D G T 2+D G T 3=C_{D G T}$

Approach 4. DGT4 $+D G T 3=C_{D G T}$

Approach 5. $D G T 5=C_{D G T}$

For Period 2, at least 3 ways can be suggested which are in Approaches 3, 4, and Approach 5. Approaches 1 and 2 allow temporal variation. The difference is the stages that the technical experts would like to capture. DGT4 includes the minimum and maximum values of concentration while the DGT3 integrated the washing effect. DGT2 describes the increase of concentration as the rainfall and the surface-run-offs have added their contribution. DGT5 covers the whole Scenario 2.

Based from the above mentioned combinations or decisions, reliable results can be generated. If episodic events are the primary concern, for example, it is good to have combinations like in scenario 1: DGT1 vs. DGT 2. Wherein, the concentrations at the start of the dredging campaign can be compared to the time wherein the dredging was on-going. It is also advisable to conduct sampling before the dredging activity. It is up to the technical expert to define the time of water sampler immersion. While, if the objective is just to see the water quality of the water DGT 5 for scenario 2 and DGT 3 for scenarios 1 and 2 could be a good recommendation. This manner considers the maximum and minimum values to be integrated in the time-weighted average concentration that DGT can provide. The ability to make comparisons and assessments is one of the advantages of series of sampling campaigns.

From the experience of the research conduct, with substantiation, the hydrological condition (season-driven) is an important factor for consideration. The baseline information obtained from this research provides better understanding of the Pasig River. 


\section{Conclusion}

Water quality assessment is a vital element. This provides basis in doing water management plans and actions. In order to provide good and solid information reliable and practical monitoring techniques should be employed. This research considered three periods (i.e. Period 1: dry and dredging; Period 2: wet to dry; and Period 3: series of rainfalls) for the conduct of the water sampling.

Classic method was employed to measure the trace metals in total fraction. Total trace metals using grab sampling provided a picture of the water quality but not enough to make a strong generalization as sampling frequency should be increased. However, this fraction can only describe the general status of the water quality. If the real concern is the risk on the aquatic system, real dissolved fraction should be considered. This fraction is found to have relation when biological and chemical reactions within the aquatic system are involved. For this reason, the use of the DGT technique was employed.

Pasig River is a dynamic system as it is a natural estuary. The environmental parameters facilitated in describing and differentiating the environmental chemistry in the water column for each period. Following this, the reliability and the sensitivity of the DGT probes were tested as they were able to capture and follow the environmental signals from different seasonal changes and episodic event.

This study was able to arrive in giving qualitative and quantitative results. For instance, it was observed that among the trace metals $\mathrm{Zn}$ do not follow the seasonal trend. This signifies that permanent contributors are present as indicated by the increase in concentration. The outcome showed the representativeness (spatially and temporally) of the trace metals (both in total and dissolved factions) in describing the status of the water. Moreover, the most problematic site was able to indentify. The results pointed out that this is the confluence near the Marikina River. The study provided a sampling design for employing 
conventional and passive approaches drawn in different scenarios. The result demonstrated that if freely dissolved fraction is of concern, the DGT technique in monitoring the water quality of the Pasig River is applicable and recommended to other different water conditions. Hence, this paper deduces that passive sampling, using DGT in this case, can be part of the routine water quality monitoring.

Water quality assessments need reliable and empirical results from practical and pertinent sampling method like the DGT technique. This paper recommends continues water quality monitoring and assessments. This is as the river is found to be dynamic and receptive to seasonal changes. In doing so, defined objective in conducting water quality measures such as on the concern on the potential ecological risks in the water. Each of the sampling procedures should correspond to the objectives of the monitoring activity. From this, local authorities should be able to provide reliable water quality information and locate the highly polluted area. For instance, in terms of the concern of the trace metal flux contribution, as previously stated, the confluence of the Marikina River was identified as the area that needs to be prioritized.

\section{Acknowledgement}

This research was funded by the Lyonnaise des Eaux Company, Bordeaux, France and was done with the help of the Pasig River Rehabilitation Commission (PRRC), LCDR Christopher Meniado of the Philippine Coast Guards (PCG) and his staff, the Department of Natural Resources and Environment-Environmental Management Bureau (DENR-EMB) and Dr. Gemma Narisma, Genie Lorenzo and James Simpas of the Manila Observatory. The authors are also grateful to the French Embassy in the Philippines for giving financial assistance for field mobility, the European Union ERASMUS MUNDUS External Cooperation Window (ECW) Lot 12/13 and the Programme Eiffel Doctorat (2012-2013) from the French Ministry of Foreign Affairs for providing the academic grant. 


\section{References}

Aisopou A, Stoianov I, Graham NJD (2012) In-pipe water monitoring in water supply systems under steady and unsteady state flow conditions: A quantitative assessment. Water Res 46:235-246

Akrami SA, El-Shafie A, Jaafar O (2013) Improving rainfall forecasting efficiency using modified adaptive Neuro-Fuzzy Inference System (MANFIS). Water Resour Manage 27:3507-3523

Alfaro-De la Torre MC, Beaulieu P-Y, Tessier A (2000) In-situ measurement of trace metals in lakewater using the dialysis and DGT techniques. Anal Chim Acta 418:53-68

Alexa N, Zhang H, Lead JR (2009) Development of a miniaturized diffusive gradient in thin films (DGT) device. Anal Chim Acta Acta 655:80-85

Allan I J, Knutsson J, Guigues N, Mills GA, Fouillac AM, Greenwood R, (2008) Chemcatcher (R) and DGT passive sampling devices or regulatory monitoring of trace metals in surface water. J of Environ Monitor 10:821-829

Aung NN, Nakajima F, Furumai H (2008) Trace metal speciation during dry and wet weather flows in the Tama River, Japan, by using diffusive gradients in thin films (DGT). J of Environ Monitor 10:219-230

Campbell PGC (1995) Interactions between trace metals and aquatic organisms: a critique of the free-ion activity model. Edited by Tessier, A and Turner DR. Metal speciation and bioavailability in aquatic systems. Chichester:Wiley pp 45-102

Carvalho FP, Villeneuve CC, Tolosa I, Bajet CM, Navarro-Calingacion MF (2009) Organic contaminants in the marine environment of Manila Bay, Philippines. Arch Environ Contam Toxicol 57:348-358 doi:10.1007/s00244-008-9271-x

CCME (Canadian Council of Ministers of the Environment) (1996) Appendix XXII-Canadian water quality guidelines: Updates (December 1996), interim marine and estuarine water quality guidelines, Canadian Council of Resource and Environment Ministers. 1987. Prepared by the Task Force on Water Quality Guidelines.

Cruz RT (1997) Case Study 111-The Pasig River, Philippines. Water pollution control-A guide to the use of water quality management principles WHO/UNEP ISBN 0419229108

Diamond JM, Winchester EL, Mackler DG, Rasnake WJ, Fanelli JK, Gruber D (1992) Toxicity of cobalt to freshwater indicator species as a function of water hardness. Aquat Toxicol 22:3: 163-179. doi:10.1016/0166-445X(92)90038-O

DGT Research (2002) DGT-for measurements in water, soils and sediments. DGT Research Ltd., Lancaster

Docekova H, Divis P (2005) Application of diffusive gradient in thin films technique (DGT) to measurement of mercury in aquatic systems. Talanta 65:1174-1178

Eggleton J, Thomas K (2004) A review of factors affecting the release and bioavailability of contaminants during sediment disturbance events. Environ Int 30:973-980

Gay D, Maher, W (2003) Natural variation of copper, zinc, cadmium and selenium concentrations in Bembicium nanum and their potential use as a biomonitor of trace metals. Water Res 37:2173-2185

Gibbs, RJ (1973) Mechanisms of trace metal transport in rivers. Science 180:71-73

Graveline N, Maton L, Luckge H, Rouillard J, Strosser P, Palkaniete K, Rinaudo J-D, Taverne D, Interwies E (2010) An operational perspective on potential uses and constraints of emerging tools for monitoring water quality. TrAC 29:5 
Han W, Moore AM, Levin J, Zhang B, Arango HG, Curchitser E, Di Lorenzo E, Gordon AL, Lin J (2009) Seasonal surface ocean circulation and dynamics in the Philippine Archipelago regions during 2004-2008. Dynam of Atmos Oceans 47:114-137

Harger JRE (1995) ENSO variations and drought occurences in Indonesia and the Philippines. Atmos Environ29:16:1943-1995. 1352-2310(94)00362-9

Hartman J, Levy J, Okada N (2006) Managing surface water contamination in Nagoya, Japan: An integrated water basin management decision framework. Water Resour Manage 20:411-430

Hartnett M, Wilson JG, Nash S (2011) Irish estuaries: Water quality status and monitoring implications under water framework directive. Mar Policy 35:810-818

INAP (2002) Diffusive Gradient in Thin-Films (DGT). A Technique for Determining Bioavailable Metal Concentrations. http://www.inap.com.au/public_downloads/Research_Projects/Diffusive_Gradients_in_Thi n-films.pdf. Accessed 28 June 2011.

Janssen CR, Heijerick DG, De Schamphelaere, Allen, HE (2003) Environmental risk assessment of metals: tool for incorporating bioavailability. Environ Int28:793-800

Khalil B, Ouarda TBMJ, St-Hilaire A, Chebana A (2010) A statistical approach for the rationalization of water quality indicators in surface water quality monitoring networks. $\mathrm{J}$ of Hydrol 386:173-185

Li W, Zhao H, Teasdale PR, Wang F (2005) Trace metal speciation measurements in waters by the liquid binding phase DGT device. Talanta 67:3:571-578

Lu Y, Wang Z, Huckins J (2002) Review of the background and application of trioleincontaining semipermeable membrane devices in aquatic environmental study. Aquat Toxicol 20:139-153

Masson M, Blanc G, Schafer J, Parlanti E, Le Coustumer P (2011) Copper addition by organic matter degradation in the freshwater reaches of a turbid estuary. Sci Total Environ 409:1539-1549

Materum R (2010) Physicochemical and particulate characterization of selected urbanimpacted aquatic systems in Manila (The Philippines) and Bordeaux (France). Rapport de Stage. FDEA. Université Bordeaux 1

Mazzei F, D'Alessandro A, Lucarelli F, Nava S, Prati P, Valli G, Vecchi R (2008) Characterization of particulate matter sources in an urban environment. Sci Total Environ 401: 81-89

Meyer JS (2002) The utility of the terms "bioavailability" and "bioavailable fractions" for metals. Mar Environ Res 53:417-423

Moreda-Piñeiro J, Moreda-Piñeiro A, Romaris-Hortas V, Dominguez-Gonzales R, AlonsoRodriguez E, Lopez-Mahia P, Muniategui-Lorenzo S, Prada-Rodriguez D, BermejoBarrera P (2012) Trace metals in marine foodstuff: Bioavalibility estimation and effect of major food constituents. Food Chem 134:339-345

Morillo J, Usero J (2008) Trace metal bioavailability in the waters of two different habitats in Spain: Huelva estuary and Algeciras Bay. Ecotox Environ Safe 71:851-859

Munksgaard NC, Lottermoser BG (2010) Mobility and potential bioavailability of trafficderived trace metals in a 'wet-dry' tropical region, Northern Australia. Environ Earth Sciences 60:7/1447-1458 doi:10.1007/s12665-099-0280-5

Nalbantis I, Tsakiris G (2009) Assessment of hydrological droughts revisited. Water Resour Manage 23:881-897. DOI 10.1007/s11269-008-9305-1 
Ouyang Y (2005) Evaluation of river water quality monitoring stations by principal component analysis. Water Res 39:2621-2635

Pattke T, Oberli F, Audétat A, Guillong M, Simon A, Hanley J, Leonhard K (2012) Recent developments in element concentration and isotope ratio analysis of individual fluid inclusion by laser ablatio, single and multiple collector ICP-MS. Ore Geol Rev 44: 10-38

Pérez A L, Anderson KA (2009) DGT estimates cadmium accumulation in wheat and potato from phosphate fertilizer applications. Sci Total Environ: 407:5096-5103

PRRC (2009) Water quality status of Pasig River system. Unpublished report

Schintu M, Durante L, Maccioni A, Meloni P, Degetto S, Contu A (2008) Measurement of environmental trace-metal levels in Mediterranean coastal areas with transplanted mussels and DGT techniques. Mar Pollut Bull 57:832-837

Severini MDF, Botte SE, Hoffmeyer MS, Marcovecchio JE (2009) Spatial and temporal distribution of cadmium and copper in water zooplankton in the Bahia Blanca estuary, Argentina. Estuar Coast Shelf S 85:57-66

Shafer M, Overdier J (1995) Analysis of surface water for Trace Metal Elements by ICP-MS. Revision 4. Water Chemistry Program. University of Wisconsin-Madison, Madison WI 53706

Sherwood JE, Barnett D, Barnett NW, Dover K, Howitt J, Ii H, Kew P, Mondon J (2009) Deployment of DGT units in marine waters to assess the environmental risk from a deep sea tailings outfall. Anal Chim Acta 652:215-223

Sondergaard J, Elberling Bo, Asmund G (2008) Metal speciation and bioavailability in acid mine drainage from a high Arctic mine waste rock pile: Temporal variations assessed through high-resolution water sampling, geochemical modelling and DGT. Cold Reg Sci Technol 54:89-96

Strobl RO, Robillard PD (2008) Network design for water quality monitoring of surface freshwaters: A review. Environ Manage 87:639-648

Tsakiris G (1988) Aggregated runoff from small watersheds based on Stochastic representation of storm events. Water Resour Manage 2:77-86

Thévenot DR, Moilleron R, Lestel L, Gromaire MC, Rocher V, Cambier P, Bonté P, Colin JL, de Pontevés C, Meybeck M (2007) Critical budget of metal sources and pathways in the Seine River basin (1994-2003). The Sci Total Environ 375:180-203

USEPA. National Recommended Water Quality Criteria.

http://water.epa.gov/scitech/swguidance/standards/current/index.cfm. Accessesed 24 April 2012

Van Den Berg GA, Meijers GGA, Van Der Heijdt LM, Zwolsman, JJG (2001) Dregdingrelated mobilisation of trace metals: A case study in the Netherlands. Wat Res 35:8: 19791986. PII:S0043-1354(00)00452-8

Vrana B, Mills AG, Allan IJ, Dominiak E, Svensson K, Knutsson J, Morrison G, Greenwood $\mathrm{R}$ (2005) Passive sampling techniques for monitoring pollutants in water. TrAC 24:10:845868

Vystavna Y, Huneau F, Motelica-Heino M, Le Coutumer P, Vergeles Y, Stolberg F (2012a) Monitoring and flux determination of trace metals in rivers of the Seversky Donets basin (Ukraine) using DGT passive samplers. Environ Earth Sci. 65, 6, 1715-1725

Vystavna Y, Huneau F, Schafer J, Motelica-Heino M, Blanc G, Larrose A, Vergeles Y, Dyadin D, Le Coustumer P (2012b): Distribution of trace elements in waters and sediments 
of the Seversky Donets transboundary watershed (Kharkiv region, Eastern Ukraine). Appl Geochem, 27, 2077-2087

Wei GL, Yang ZF, Cui BS, Li B, Chen H, Bai JH, Dong SK (2009) Impact of Dam Construction on Water Quality and Water Self-Purification Capacity of the Lancang River, China. Water Resour Manag 23:1763-1780 doi: 10.1007/S11269-008-9351-8

Wetzel RG (2001) Limnology. Lake and river ecosystem $3^{\text {rd }}$ Edition. Elsevier. Academic Press USA

Winn PJS, Young RM, Edwards AMC (2003) Planning for the rising tides: the Humber Estuary Shoreline Management Plan. Sci Total Environ 314-316:13-30

Wu Y, Falconer R, Lin B (2005) Modelling trace metal concentrations distributions in estuarine waters. Estuar Coast Shelf S 64:699-709

Yapici T, Fasfous II, Murimboh J, Chakrabarti CL (2008) Investigation of DGT as a metal speciation technique for municipal wastes and aqueous mine effluents. Anal Chim Acta 622:70-76

Zhang H, Davison W (1995) Performance characteristics of diffusion gradients in thin films for the in-situ measurements of trace metals in aqueous solution. Anal Chem 67:3391-3400

Zhang H, Davison W (1999) Diffusional characteristics of hydrogels used in DGT and DET techniques. Anal Chim Acta 398:329-340

Zheng J, Takata H, Tagami K, Aono T, Fujita K, Uchida S (2012) Rapid determination of total iodine in Japanese coastal seawater using SF-ICP-MS. Microchem J 100:42-47

Zwolsman JJG, Van Eck BTM, Van der Weijden CH (1997) Geochemistry of dissolved trace metals (cadmium, copper, zinc) in the Scheldt estuary, southwestern Netherlands: Impact of seasonal variability. Geochim Cosmichim Acta 61: 8:1635-1652 